\title{
América Latina y los países no alineados*
}

\begin{abstract}
CARLOS E. PÉREz LLANA, Graduado en la Universidad Nacional de Rosario, Profesor de Política Internacional en la ciudad de Buenos Aires y en la Universidad de Mar del Plata, es Director de Relaciones Exteriores de la República Argentina. Ha publicado: Perú en el Concierto Mundial; Estudio y Regionalidad.
\end{abstract}

\section{ASPECTOS TEÓRICOS}

Como cuestión previa al tratamiento del tema resulta imprescindible la clarificación conceptual. En efecto, desde la Conferencia de Bandung en 1955 el término no-alineación constituye una categoría confusa, en cuanto al contenido, dentro de las relaciones internacionales.

Es más, según los enfoques aparece el término bajo otras nomenclaturas como ser: Tercer Mundo, Tercera Posición, Neutrales, etc. Cabe entonces precisar la unidad de análisis, así descalificamos los términos de "países neutralistas", "tercermundistas" y "Tercera Posición" no sin antes precisar brevemente el contenido que les asignamos a estas definiciones.

Una posición neutralista precisamente no es la sustentada por los países en cuestión. En términos socio-políticos la correspondencia se daría en el no-compromiso.

Sin embargo, los países no-alineados de ninguna manera pretenden para sí un papel de marginamiento como el fenómeno mismo de la neutralidad presupone; por el contrario, en reiteradas oportunidades se han manifestado como definidos actores de la vida internacional.

No cabe entonces conceptualizar criterios de espectadores pasivos. Asimismo rechazamos la idea de una neutralidad definida en términos jurídicos o sea un estatuto legal en tiempos de guerra o neutralidad "armada" como puede ser la de Suecia que, si bien no pertenece a ningún sistema de seguridad militar, no deja de poseer un sofisticado aparato militar.

* Este trabajo forma parte de una publicación de Edit. Pleamar referida a la problemática latinoamericana. 
Tal vez el origen de esta confusión -neutralidad y no-alineaciónradique en la reiterada manifestación en documentos y resoluciones del principio que sostiene la necesidad de dirimir los conflictos por medios pacíficos. Así el punto $8^{\circ}$ de la Declaración. Final de Bandung expresa: "Arreglo de todas las diferencias internacionales por medios pacíficos, tales como conversaciones, conciliaciones, arbitrajes y decisiones de justicia y por aquellos otros medios igualmente pacíficos que sean elegidos por las partes de conformidad con la Carta de las Naciones Unidas".

Como se observará el principio es claro, aún más, subyace en el enunciado una "actitud espiritual" sui géneris en tiempos de paz. Sin duda alguna, de existir la filosofía de la no-alineación este principio constituiría la idea-fuerza dado que del mismo se deducirían una infinidad de criterios como ser: no intervención, no presión, solidaridad, vigencia plena de un derecho de cooperación interestatal, etc.

Sin embargo la realidad no deja de presentarnos "comportamientos desviados". Así, desde los inicios del grupo de los no-alineados la teoría no cesaba de afirmar la "repugnancia" de la India a toda "visión militar" o enfoque clásico del poder en las relaciones internacionales.

La ocupación militar de la colonia portuguesa de Goa señaló un hito muy particular. Si bien es cierto que esta ocupación se daba en un contexto colonial al cual Nehru combatía desde el Congreso de los Pueblos Oprimidos 1 , la misma característica militar no dejó de asombrar.

El equipamiento militar no cejó bajo el gobierno de Nehru; la. ocupación china en el Tíbet, los problemas fronterizos con ese país y muy particularmente el problema de Cachemira con el Pakistán fueron instrumentados como justificadores del no cumplimiento de la "cruzada pacifista".

La culminación de esta presencia militar se trasluce en el conflicto bélico del pasado año entre la India y el Pakistán en donde la heredera del Pandit no dudó en aplicar el dispositivo militar constituyéndose en garante del nacimiento - por la vía secesionista- de la República de Bangla Desh.

No cabe en este análisis asignar culpabilidades, pero sí constatar un hecho. Ambos países (India y Pakistán) asistieron en 1954 a la Reunión de Colombo junto a Birmania, Indonesia y Ceilán y más luego a la Reunión de Bogor en donde se instrumentara la Conferencia Cumbre de Bandung.

'Este Congreso se celebró en febrero de 1927 en Bruselas. Si bien es cierto que desde 1920 se venían organizando este tipo de reuniones, es aquí donde se postulan por vez primera los principios del Grupo. 
Casos similares de "comportamientos desviaclos" en donde la "actitud espiritual" en tiempos de paz no ha sido de aplicación no faltan.

Recordemos entre otros la ingerencia egipcia y saudita en el conflicto del Yemen (República Arabe del Yemen); la entrada de tanques sirios en el reino jordano y la abierta participación de Libia en los intentos golpistas de 1971 y 1972 en Miarruecos.

De manera que si bien existen compromisos respecto al uso de la fuerza, esto de ninguna manera ha significado la no transgresión del principio. Aparentemente esta actitud respecto a la neutralidad -en el sentido del no uso de la fuerza armada y el correspondiente no compromiso en el sentido de la no ingerencia- no dejan de ser el resultado de conclusiones "realistas" que tienen como marco de referencia $y$ destinatarios a las grandes potencias y a sus politicas de bloque.

Concluimos el análisis de la definición neutralista y del no compromiso con una declaración de Nehru, formulada en una conferencia de prensa al "New York Herald Tribune", la cual avala nuestra afirmación en cuanto al sentido "realista" (nada espiritualista por cierto) de ciertos principios.

Declaraba Nehru en marzo de 1948 ante el Parlamento indio:

"Desde un punto de vista puramente oportunista, lo mejor nos parece ser una política independiente. Lo que tal política debería ser nos resulta difícil decirlo ahora porque las cosas evolucionan día a día. Podría ser que nos viéramos llevados a elegir en ciertas circunstancias el mal menor. Podría ser que tuviéramos que colocarnos del lado de la potencia imperialista, y no tengo vergüenza de decirlo, al menos si éste fuera el mal menor. Nada es más importante que convertir a la India en un país económicamente fuerte; intentaremos obtener para eso ayuda de otros países, pero de todos modos sería poco inteligente apostar todas nuestras fichas a un solo número"."

Es frecuente también la caracterización de Tercer Mundo para este conglomerado de países. Así para Robert Bosc esta categorización engloba tanto al África como a los continentes asiáticos y americanos. Según este prestigioso sociólogo de las relaciones internacionales, el término Tercer Mundo aludiría al discurso de Sièyes ante los Estados Generales de la Francia de 1789. Así la analogía estaría dada por el hecho de que al igual que el Tercer Estado en Francia (hasta la Revolución Francesa) este conglomerado no sería nada

"Ver cita en Vandeweghe (luc), Le neutralisme afro-asiatique, "Chronique de Politique étrangère", París, marzo de 1960, p. 192. 
(en términos de poder), estaría presente en todas partes y políticamente "querría ser algo".

Greemos que el concepto a fuer de ser expresivo es generalizante. Dentro de esa heterogeneidad coexisten especificidades que necesitan de un tratamiento particular.

Así resulta prácticamente imposible detectar indicadores comunes entre países tan dispares. Aun si se pretende destacar el hecho de ser Estados más o menos recientes, queda. América Latina fuera del enfoque.

Demás está señalar la heterogeneidad de los sistemas políticos. Los de "movilización", las "autocracias modernizantes" y los de reconciliación" conviven con monarquías tradicionales, democracias dirigidas, populismos, social-democracias, parlamentarismo reformista, statuquista tradicional, socialismos, etc. ${ }^{3}$

Existe también una interpretación del Tercer Mundo en términos de cultura. Así se podría entender el rol de estos países como iniciadores de una "contra-cultura". En el marco de una "dialéctica planetaria" se inscriben las teorizaciones de algunos socialistas africanos - cargadas de una ética de culpabilidad para con el mundo blanco-; el planteo del Che Guevara referido a la creación de "varios Vietnams" y del ex heredero de Mao, Lin Piao, cuando se refiere (con un gran énfasis en el simbolismo asiático) al "campo", en este caso los países proletarios del Tercer Mundo, y a la "ciudad" pretendidamente amenazada -los países desarrollados entre los que incluye a la Unión Soviética.

Aun así el deslinde es dificultoso. ¿Hasta qué punto existe un común criterio (por parte de estos países) de cuestionar y a la vez ofrecer una alternativa a la sociedad consumista, sea ésta capitalista o socialista? ¿Hasta qué punto es posible asimilar e interpretar en un mismo contexto a culturas tan cliversas como son la asiática, la africana (con el particularismo islámico) y la latinoamericana?

La visión del guevarismo ortodoxo y la metáfora de Lin Piao nos acercan más bien al terreno de los fenómenos políticos. Es en este campo -el político- donde la caracterización responde a posiciones e interpretaciones más o menos comunes.

Según algunas interpretaciones nos encontraríamos frente al germen del "gran partero" del socialismo. En este caso dicha función correspondería al Tercer Mundo. Se estaría produciendo una traslación, el proletariado nacional sería reemplazado por el "proletariado internacional".

Para otros enfoques lo común a todos estos países radicaría en fe-

${ }^{3}$ Esta tipología pertenece a Apter, David E., Industrialization and Society, editado por Bert F. Hosclitz, Unescowlouton, 1963. 
nómenos económico-políticos muy concretos. El principal de ellos sería aquel común denominador que los presenta unidos en un rol subordinado frente a los países desarrollados como consecuencia del deterioro creciente que sufren en sus economias.

Desestimamos la versión "planetarista" (aun aceptándola como instrumento de interpretación teórica, las heterogeneidades señaladas atentarian contra la operacionalidad del planteo) y, por el contrario, interpretamos como más coherente la pretendida homogeneidad de todos estos países frente a un fenómeno que les toca por igual como ser el continuo deterioro frente a las economía del "centro".

Asi este conjunto de países padece un retroceso relativo en el precio de sus productos en el mercado internacional (con algunas excepciones como ser el aumento del precio del petróleo, el azúcar y el yute). Mientras las naciones industrializaclas aumentaron sus exportaciones en 1971 en un $11 \%$ (en 1970 el $15,5 \%$ ), los países de insuficiente desarrollo sólo consiguieron incrementar sus envíos en un $9 \%$ (en 1970 lo habían hecho en un 11,6\%).

Aceptando como aproximativa esta interpretación de la real existencia - como bloque de países- del Tercer Mundo, creemos que esta conceptualización no reemplaza ni tampoco corresponde a la categoría de no-alineados.

Por último cabe distinguir no-alineación de Tercera Posición. Desde el punto de vista teórico la distinción es clara.

No-alineación supone no adscribirse (de allí la historicidad del término) a ningún bloque. La perspectiva nos la da el sistema bipolar de los años 50, en plena "guerra fría".

Frente a intereses contrapuestos, los Estados Unidos y la Unión Soviética pretendían universalizar el conflicto en términos ideológicos: mundo libre vs. países comunistas.

Decíamos que teóricamente la distinción resulta clara. Las evidencias nuevamente desmentirán a los principios. Así, el punto $5^{\circ}$ de la Declaración de Bandung expresa:

"Reconocimiento de los derechos de cada nación en materia de defensa individual o colectiva según la Carta de la Naciones Unidas".

El análisis histórico ayuda a interpretar en sus justos términos este nuevo ejemplo de "conducta desviada" (al ser admitida la incorporación a pactos de seguridad colectiva obviamente inspirados por los Estados Unidos o la Unión Soviética).

Cuando la comisión política de la Reunión de Bandung trató los temas de la paz y de la cooperación internacional los partidarios de la ortodoxia (en este caso el rechazo a todo tipo de incorporación 
a los bloques), liderados por Birmania, sostuvieron la vigencia de los "5 Principios" aprobados entre China Continental y la India en 1954 con motivo de la visita que efectuara el premier chino Chou En Lai.

A esto se opuso Pakistán quien a la ortodoxia contrapuso los denominados "siete pilares de la paz", uno de los cuales se refería al "derecho para todo país de defenderse solo o colectivamente", o sea, se justificaba la afiliación a pactos de seguridad colectiva. Al respecto el Pacto de la SEATO ya había sido suscrito por tres países asistentes a Bandung: Tailandia, Pakistán y Filipinas; mientras los paises árabes -Jordania e Irak- negociaban el Pacto de Bagdad que seria firmado en noviembre de 1955 .

El tema se vuelve a repetir en la Reunión Preparatoria de El Cairo, en junio de 1961, convocada a iniciativa de Indonesia, Yugoslavia, Afganistán, India y Egipto. Allí se pretende fijar los criterios básicos del no-alineamiento para luego cursar las respectivas invitaciones para la Conferencia de Belgrado de 1961.

Sin embargo nunca se logró un acuerdo mínimo respecto del tema, y es así que países como Jordania - con expresos compromisos militares pactados- siguen siendo considerados miembros plenos de los no-alineados.

A pesar de las contradicciones como la anteriormente señalada, teóricamente la no-alineación supone la no adscripción a ningún bloque. O sea que en la actual conformación multipolar del sistema internacional ("pentarquía polar" integrada por EE.UU., URSS, Japón, China y Europa) el principio permanece en vigencia pero adaptado a la nueva realidad: en vez de rechazar la afiliación a dos bloques se debe rechazar la afiliación a cualquiera de los cinco.

La Tercera Posición puede ser a la vez definida según dos enfoques: como posición meramente internacional o como una concepción que hace a la naturaleza misma de los sistemas políticos y económicos.

Si bien es cierto que la política exterior de un país constituye la resultante del sistema político nacional, se puede presentar el caso cle una Tercera Posición en lo externo que pretenda convertirse como polo de atracción.

Para ello no es mecesario una concepción original que enfrente al capitalismo o al colectivismo. El caso de la Francia de De Gaulle avala nuestra afirmación.

En efecto, un capitalismo nacional emergente si no puede negociar en términos que considere justos con el capitalismo hegemónico y poseyendo a la vez suficiente potencial político-militar, puede aventurarse a cuestionar la política de bloques desconociendo en consecuencia las áreas de influencia. Todo esto sin postular ninguna nove- 
dosa concepción sobre el hombre, el trabajo, la justicia o la libertad; sólo presenta una vaga idea de democratización internacional, pero al fin interesada en atraer para sí adeptos.

La contrapartida es la 'Tercera Posición como alternativa ideológica, o sea, una nueva concepción de tipo valorativo respecto del mundo, del hombre y de la sociedacl. El primer enunciado de este tipo - por lo menos a nivel gubernamental y con vigencia políticalo constituyó el tercerismo peronista. El tema será tratado más adelante; aquí sólo se trata de ejemplificar nuestra clasificación.

Este tipo de Tercera Posición se presenta como una doctrina que pretende superar la lucha de clases, el individualismo liberal y el colectivismo marxista. Lógicamente esta concepción, al implementársela desde el gobierno, se proyectó a la comunidad internacional constituyéndose en un tercerismo internacional que respondía a un intento societario singular. En este caso existe también correspondencia histórica: Tercera Posición como "tercera concepción" y a la vez Tercera frente a dos bloques internacionales.

EL CONCEPTO DE LA NO-ALINEAGIÓN, INTERPRETACIONES Y DESARROLLO FISTÓRICO

Aceptando la delimitación que el término no-alineado supone, varían las interpretaciones.

Así para algunos autores se trataría de una concepción genérica sobre política exterior. Crabb, Babaa -entre otros- la sostienen como una doctrina de política exterior. 4

El término política exterior no debe confundirse con la explicitación de metas y cursos de acción. Se aproxima más bien a una visión arquetípica del mundo - weltanschauung-.

Con un acento pragmático otras interpretaciones quieren ver en la no-alineación un tipo muy particular de política exterior constituida por la suma de orientaciones - en materia externa- de un determinado número de países.

Por fin, autores como Burton proponen a la no-alineación como un nuevo sistema de relaciones que corresponden a los cambios ocurridos en el sistema internacional a partir de la segunda Guerra Mundial. Así nos encontraríamos ante un nuevo esquema de las relaciones internacionales, la alternativa al tradicional sistema de poder.

"Crabb, C., Nonaligment in World Affairs, introduction. "The Annals of the American Academy of Political and Science", noviembre 1965, p. 4. 
Como se habrá observado, todos estos marcos interpretativos insisten en una aproximación generalizante. Se pretende englobar una heterogeneidad en una categoría unitaria. De allí que pensamos que el procedimiento debe ser inverso y en consecuencia sostenemos como hipótesis lo siguiente:

No existe la categoría univoca y estática de la no-alineación. Por el contrario, cada país o grupo de paises tiene una interpretación propia según sus propios intereses y las circunstancias históricas.

Greemos que esta aproximación operacional es lo suficientemente flexible como para poder interpretar la multitud de heterodoxias que ofrecen los países que a sí mismos se denominan no-alineados.

Así podremos elaborar categorías de análisis racionales; de lo contrario habría que otorgar validez a muchos dogmatismos y determinismos que no alcanzan a interpretar una realidad por lo demás compleja.

Bien podemos caracterizar como de no-alineación la postura de un determinado país en la década del 50 sin que por eso aceptemos como válida la denominación en términos actuales para el mismo país por el solo hecho de ser miembro pleno en las conferencias de no-alineados.

Coherentemente con nuestra hipótesis sostenemos que a cada tiempo histórico" corresponde una temática particular de no-alineación de manera que el desarrollo del proceso desde Bandung hasta la fecha nos ejemplificará la singularidad mencionada.

\section{Lia no-alineación y el liderazgo asiático (1945-1955)}

Este período está determinando el inicio del movimiento de la no-alineación. La entente aliada llega a su fin, fracasan las esperanzas de una posguerra con justicia y paz.

La guerra fría entre Oriente y Occidente se traslada a todos los órdenes de la vida internacional, se universaliza el conflicto en función de las ideologías.

Para los Estados Unídos y la Unión Soviética la lógica del sistema internacional era "conmigo o contra mi". La posición era coherente, cuando el conflicto alude a intereses cabe la negociación, mas cuando aparecen en juego valores (en este caso ideologías) no cabe la negociación y en consecuencia las reglas de juego no son flexibles.

Por esos años el concierto de naciones todavía no se había visto sacudido por el movimiento descolonizador. Así en las Naciones Uni- 
das sólo ingresan en este lapso Afganistán, Birmania, Yemen e Israel.

De allí la escasez de acciones contestatarias; sin embargo, en los líderes de los movimientos nacionalistas que luchaban por la liberación de sus países la idea de no adscribirse a ninguno de los bloques era mayoritaria.

Para muchos asiáticos y africanos el conflicto este-oeste no dejaba de ser un problema de blancos. En 1947 se produce la primera declaración oficial de la no-alineación: la India.

Las reuniones de Gasablanca y Bogor preanuncian la impronta de Bandung; el conflicto de Corea, la consolidación de Mao y los reveses franceses en la Indochina habian modificado sustancialmente la estructura colonial.

\section{La "africanización" de la no-alineación (1955-1961)}

EI anticolonialismo militante había constituido el tema fundamental en la primera etapa. A partir de Bandung la preocupación de los no-alineados giraba en torno a la presión de las grandes potencias para atraerlos a sus respectivas áreas de influencia y el común temor a. verse envueltos en una conflagración bélica.

Con respecto al interés soviético-norteamericano cabe diferenciar la estrategia de ambos. Estados Unidos, sosteniendo una visión clásica de la eventual expansión comunista o sea la invasión por tierra cuyo ejemplo reciente era Corea, pretendía cauterizar Asia a través de Ios pactos militares al tipo de la OTAN.

Doblemente equivocada resultó la estrategia. En primer lugar Corea significó el fin del expansionismo militar clásico del bloque soviético. Ya con anterioridad a la muerte cle Stalin (1953) dicha concepción había sido suplantada por la propaganda masiva, la divulgación de ideas, ayuda, envio de delegaciones y la guerrilla en to militar. En segundo lugar, la filosofía que animaba los pactos del Secretario de Estado norteamericano F. Dulles tenía como presupuesto básico la existencia de un enemigo común para todos los países que firmaban y suscribian la tesis pactista, como lo era para los países de la OTAN el temor soviético.

Sin embargo para Pakistán - por citar sólo un ejemplo- el enemigo no lo constituía ni Pekín ni Moscú, era la India. Mal podían estos pactos constituir una estrategia apta para atraer aliados.

Fue Kruschev quien termina de flexibilizar la estrategia soviética para con los no-alineados. A partir del XX Congreso (1956) los nacionalismos africanos y asiáticos reciben el total apoyo ruso. Nasser, entre otros, consigue todo tipo de ayuda y solidaridad.

El otro tema de preocupación de estos países lo encontrábamos 
en el temor de una nueva guerra, esta vez de carácter nuclear. Esto explica el acento puesto por la Declaración de Bandung en el tema de la coexistencia.

Con estas características (bloques, guerra fría, coexistencia) nace la no-alineación, o sea, no adscripción a los bloques (siempre en el plano de lo teórico, pues ya había excepciones) e intentos de ejercitar un papel de moderador entre las potencias en pugna. A estos dos aspectos cabe agregar las reivindicaciones anticolonialistas, antirracistas y la reiterada apelación a la mutua ayuda.

Calificamos al período como de "africanización" y esto es así, pues por estos años inmumerables países africanos acceden a la vida independiente transformando la relación de fuerzas dentro de los no-alineados que hasta ese momento favorecía a los Estados asiáticos.

\section{El intento "democratizador": de Belgrado a El Cairo (1961-1964)}

La reunión sobre asuntos económicos de El Cairo en 1962 marca la transición y a la vez refleja la idea que estos países tienen del sistema internacional.

Insisten en los postulados de la coexistencia pero ahora la definen dentro de un contexto que le da especial sentido: la solidaridad entre los pueblos obrará en favor de la democratización de la vida internacional.

El tema económico aparece ya con cierto énfasis en este período; en El Cairo en 1962 se dan los primeros pasos en este sentido. La colaboración económica internacional, los problemas del comercio y la ayuda al desarrollo adquieren relevancia para llegar finalmente a la reunión de El Cairo de octubre de 1964.

En un segundo plano se reitera el principismo - muy caro a los Estados africanos-, los pronunciamientos contra el colonialismo, el antimperialismo, la lucha contra el racismo y caso particular de Sudáfrica.

El multipolarismo y las contradicciones internas (1964-1972)

A partir de la reunión de El Cairo en octubre de 1964 los encuentros de los no-alineados se repiten con mayor asiduidad. La cronología es la siguiente: Reunión Consultiva de Embajadores en Belgrado, marzo de 1965; Reunión Tripartita en Nueva Delhi con la asistencia de Nasser, Tito e Indira Gandhi; Conferencia Consultiva 
de Belgrado, julio de 1969; Reunión de Ministros de Relacione Exteriores en las Naciones Unidas, setiembre de 1969; Conferencia de Colombo, marzo de 1970; Conferencia Preparatoria de Dar-Es-Salam, abril de 1970; Conferencia de Lusaka, setiembre de 1970; Reunión Preparatoria de Kuala Lumpur, mayo de 1972, y la reciente Conferencia de Guyana, en agosto de 1972.

Resulta dificultosa la tarea de seleccionar temas preponderantes en cada una de las reuniones celebradas en este período; de allí que se salvará esta falencia señalando notas particulares y tendencias predominantes.

En primer término cabe señalar brevemente los cambios ocurridos en el sistema internacional. De la ortodoxia de la "guerra fría" se pasa a una conformación multipolar, previa transición por el bipolarismo flexible.

EI "deshielo" por el cual bregaron los no-alineados en la década del 50 provocó en estos países notorios desfasajes dado que insistían en una problemática ya superada o aparecían sin rumbo en el concierto internacional -habían perdido "el libreto" y no acertaban en la búsqueda del reemplazo.

La "Revolución Tecnológica" posibilita a la vez el continuo ensanchamiento de la brecha entre los países desarrollados y los que están en vías de serlo.

La disuasión nuclear y el consecuente "equilibrio del terror" hacen impensable un enfrentamiento nuclear entre las grandes potencias. Estas no sólo conocen los costos de un eventual conflicto sino que tratan de racionalizar la competencia armamentista, es la fase del "equilibrio de la prudencia".

Europa constituye una realidad, la idea degaullista sobrevivió a su creador, mientras en el bloque socialista el policentrismo se impone.

En el contexto asiático China desempeña el rol de potencia. El mundo ha cambiado, las reglas de juego en el concierto internacional responden a las nuevas circunstancias. Las reuniones de los países no-alineados también reflejan esta nueva realidad, pero a la vez que esto sucede no logran uniformar sus criterios y preocupaciones.

Así en la Reunión Consultiva de Belgrado -marzo 1965- Ios 14 representantes allí reunidos no pudieron llegar a un mínimo de acuerdo sobre el conflicto de Vietnam.

De allí en adelante la cuestión indochina adquirirá una importancia desmesurada. No le desconocemos importancia al tema, pero creemos que para el movimiento de los no-alineados no le ha significado ventajas positivas el hecho de discutir (a veces ocupando más del $50 \%$ del período de sesiones) a quién le cabe ocupar el puesto oficial si al gobierno de Saigón o a los representantes del Gobierno 
Revolucionario, tal como sucedió, por ejemplo, en la reunión de Dar-Es-Salam.

Nuestra tesis sostiene que durante esta última fase del movimiento de los no-alineados, estos países no han podido elaborar una estrategia común debido a que previamente hubiera correspondido precisar con exactitud el o los temas en donde la preocupación fuera común.

Confirmando nuestra tesis, la realidad muestra esta diversidad. Los particularismos reemplazan a las categorías universales. África presenta sus inquietudes, el racismo y el colonialismo. Los países árabes otorgan prioridad al problema palestino.

Se podrían seguir enumerando casos de particularismo. He aquí el dilema para los no-alineados: o encuentran el "tema" que les dé el sentido unitario o bien pasará el movimiento a la historia no dejando por ello de haber sido un instrumento eficaz en el proceso de democratización del sistema internacional.

La alternativa a tan dolorosa disyuntiva pareciera ser la de Julius Nierere (presidente de Tanzania) quien al dejar inaugurada la reunión de Dar-Es-Salam asignó a los no-alineados un objetivo unitario: superar la pobreza y el atraso de estos pueblos; de no ser así, afirmó, finalmente las divisiones preponderarán.

\author{
AMÉRICA LATINA
}

Para el análisis de las relaciones entre América Latina y los países no-alineados, metodológicamente procederemos de la siguiente forma. Señalaremos las especificidades latinoamericanas con respecto a África y Asia y luego estableceremos las relaciones entre los modelos políticos y sus vinculaciones externas.

Sin duda alguna los "tiempos" históricos nada tenían de común para América Latina, Asia y Africa en el momento de la creación de este conglomerado de los no-alineados.

Esto es así por una serie de circunstancias. Culturalmente son realidades distintas ya sea para el periodo anterior a la colonización como los tipos mismos de relaciones entre las metrópolis y colonias durante y después de la llegada de los europeos. En África la colonización se realiza sobre un régimen tribal consolidado mientras que a la vez la misma se da en una etapa muy particular del sistema capitalista.

Para América Latina la descolonización carece del valor político que le asignan los países africanos aun sin desconocer los casos de las Malvinas, Belice y el caso del Canal de Panamá. 
Diferencias fundamentales presentan también sistemas económicos. América Latina -en mayor o menor medida- ha superado el estadio de la economía "tradicional" y ha entrado en el desarrollo industrial por la vía "sustitutiva". Para algunos países este modelo de clesarrollo industrial se inicia en la década del 20, mientras que Africa y Asia (salvo algunas excepciones) mantienen aún una estructura agraria.

La conformación social también nos presenta diferencias sustanciales. Las tribus y etnias africanas, la sociedad cuasi feudal de algunos países asiáticos, no guardan relación alguna con los sistemas sociales latinoamericanos (no desconocemos para el continente casos aberrantes).

La producción de ideas y valores es también disímil. Latinoamérica ha amalgamado la tradición europea - a veces desplazando sistemas de valores, a veces logrando simbiosis-. Asimismo, para América existen valores esenciales pero que no son tales para los países africanos y asiáticos, como lo es el valor libertad entre otros.

En lo que hace a los sistemas politicos, a pesar de la diversidad latinoamericana, las diferencias son notables. El Estado asiático y africano se encuentra en proceso de consolidación mientras que en Latinoamérica esto se logra en el siglo $\mathrm{xrx}$ girando actualmente, en este continente, la problemática en torno al tipo de sistema político -en términos de mecanismo de distribución del poder- y a la función que le cabe al Estado en la vida socio-económica. De manera que la estructura estatal latinoamericana posee una burocracia y a la vez cierto grado de consenso.

En materia de relaciones internacionales también destacamos particularismos. Para Latinoamérica la vinculación externa se basó en un triángulo, dos de cuyos lados eran Gran Bretaña y Estados aiclos.

Históricamente Gran Bretaña fue el "lado" trascendente que ocupó el vacío dejado por las metrópolis al momento de la independencia. Luego fue desplazada por Estados Unidos (primeramente del Caribe), no sin antes combatir, a veces sin llegar a conflictos indirimibles (como lo era la competencia de los frigoríficos en la Argentina) y otras llegando a situaciones de fuerza (guerra del Chaco).

Para América Latina el tema básico de contestación son sus relaciones con Estados Unidos y con el capital internacional. En el caso de Africa y Asia lo que con mayor énfasis se cuestiona son los resabios del colonialismo y las rigideces neocoloniales. Sin embargo, a pesar de estas disputas, en líneas generales estos dos continentes mantienen con el "centro" relaciones más armoniosas que las existentes entre este último y algunos países latinoamericanos. 
Pensando en la política de bloques y el consecuente enfrentamiento de intereses en torno a las hegemonías, no se puede desconocer la particularidad latinoamericana. Este continente, dentro de las esferas de intereses, se hallaba inserto en la órbita norteamericana -a pesar de la contestación de algunos regímenes en algunos momentos, como el caso de Arbenz y Perón-, de manera que la presencia rusa y china no guarda relación con la similar en Africa y Asia en donde las hegemonías compiten en términos económicos, políticos y militares.

Esta misma situación de escenario de confrontación (África y Asia) inter-bloques posibilitó, en estos dos continentes, un mayor poder de negociación.

A estos países les fue posible negociar su posición de no-compromiso, de amenazar con el apoyo militar, abastecimiento y préstamos de las potencias en pugna en el caso de que una de ellas les negara apoyo. Pensemos así en el poder de negociación y extorsión con que contaba Nasser y comparémoslo con un régimen similar latinoamericano.

Para este continente el poder de amenaza se reducía a dos vías: la política de "continentalización" latinoamericana y el inicio o profundización de relaciones diplomáticas y comerciales con los países socialistas.

Tampoco está al alcance de América Latina un papel de moderador en Ios grandes conflictos internacionales. Esto, que entre otras cosas se clebe a la periferalidad geográfica, condiciona y limita el logro de los beneficios que el papel de moderador a veces apareja.

De ninguna manera se debe deducir, para el continente latinoamericano, una intencionalidad no favorable a la mediación. Nuestra afirmación es válida para los conflictos de trascendencia mundial (como ser los de Corea, Berlín, Vietnam, etc.), pues dentro del continente ha habido instancias moderadoras, como lo demuestran varios casos (Conferencia del Niágara, relacionada al conflicto México-Estados Unidos; Saavedra Lamas en la guerra del Chaco y Frondizi-Quadros para el conflicto Cuba-EE.UU.) .

El hecho es que sí existe la conciencia moderadora, mas por los condicionamientos, la misma es "insular". Tanto es así que la actitud moderadora latinoamericana en los conflictos de envergadura (Medio Oriente y Pakistán vs. India, entre otros) es la excepción que confirma la regla y además las causas de estos particularismos las debemos atribuir a otras intencionalidades, como ser la brillantez de algunos diplomáticos o a la incesante búsqueda de prestigio. 
LOS SISTEMAS POLÍTICOS LATINOAMERICANOS Y LA POLİTICA. EXIERIOR INDEPENDIENTE; UNA APROXIMACTÓN A LA NO-ALINEACIÓN

Al señalar las especificidades de América Latina precisamos el límite de su capacidad de negociación. De allí que los regímenes políticos que en este continente cuestionan las relaciones con la potencia hegemónica deban tener presente en todo momento las circunstancias coyunturales y en función de ellas optimizar al máximo su autonomía o sea llegar al límite de las "líneas de borde".

Con anterioridad a las referencias de los no-alineados en América Latina ya se mencionaba la problemática independentista en materia de política exterior. En esta posición se ubicaban las más diversas corrientes del espectro ideológico, como ser: los revolucionarios mexicanos, las distintas corrientes nacionalistas, la social-democracia y los populismos.

La Revolución Mexicana sin duda alguna constituyó el suceso político más significativo en la América. Latina de los años 20. La política exterior de la revolución pretendía estar al servicio de dos objetivos que eran a la vez los de la revolución: la reforma agraria y la reversión al Estado de los recursos naturales.

Este esbozo nacionalista no pasó de ser una buena intención. A la difícil situación interna se le vino a agregar la presión norteamericana manifestada -entre otras cosas- en el no reconocimiento al gobierno de Obregón.

Los principios acordados en los Pactos de Bucarelli (firmados entre MTéxico y EE.UU.), señalaron la posposición de los objetivos revolucionarios. En materia petrolera México se compromete a no aplicar las disposiciones del artículo 27 de la Constitución (aquí se consagra el dominio del Estado sobre los recursos naturales) en los casos de intereses norteamericanos. Igual criterio se estipuló en materia de tierras: las expropiadas a ciudadanos norteamericanos se debían compensar en efectivo, mientras que para el resto el Estado indemnizaba en bonos.

A pesar de este "freno" revolucionario, el principismo seguía siendo sostenido por los dirigentes mexicanos para los cuales los Pactos de Bucarelli, si bien eran una afrenta a la revolución, no admitían disyuntiva dada la infinita capacidad de retorsión con que contaba Estados Unidos. Así México financia en 1927 el Congreso de los Pueblos Oprimidos (celebrado en Bruselas, el cual constituye un antecedente de las posturas no-alineadas).

En la década del 30 México revolucionario trata de dar nuevo 
brillo a su posición internacional. En 1931 adhiere a la. Sociedad de las Naciones repudiando a la Doctrina Monroe tal como se la había incorporado al artículo 21 del Pacto.

En las conferencias panamericanas de Montevideo (1933) y Buenos Aires (1936) México sostiene firmemente el principio de la no intervención y brega por la aceptación a nivel panamericano del mismo.

En 1938 se nacionaliza definitivamente la riqueza petrolera, ratificándose la independencia externa del país.

Anteriormente señalamos que dada la periferalidad geográfica y por ser Latinoamérica una zona que gira alrededor de la influencia norteamericana, las actitudes independentistas muchas veces se expresaban en el establecimiento o profundización de las relaciones con la. Unión Soviética. México ratifica el principismo y establece relaciones diplomáticas con la Unión Soviética en 1924.

$\mathrm{El}$ hecho no dejaba de tener trascendencia. Así el Comisario soviético de Relaciones Exteriores declaraba en Moscú: "Hemos obtenido éxito en el restablecimiento de relaciones diplomáticas con el vecino de los Estados Unidos, México, hecho que nos da una base política en el continente.. México nos da así una muy conveniente base política en América para el desarrollo de nuestros futuros nexos". 5

Posteriormente la burocratización de la revolución, la consolidación de la burguesía y las nuevas reglas de juego - tanto internas como externas- darán forma y contenido al modelo económico posrevolucionario.

La política exterior es totalmente funcional a este modelo. Por un lado reitera, en algunas circunstancias, los postulados revolucionarios y por el otro se preocupa de las relaciones con su poderoso vecino.

México ha aprendido a vivir en buenos términos con los Estados Unidos y sus relaciones las caracterizamos como "especiales". No en vano es preponderante la presencia norteamericana: en el sector inversiones el $74 \%$ de las efectuadas recientemente en México son de ese origen mientras que el $60 \%$ del comercio externo mexicano se realiza con los Estados Unidos.

Las relaciones que México mantiene con Cuba al margen de la decisión de la Conferencia de Punta del Este se suelen tomar como un ejemplo del principismo de la tradición revolucionaria. Sin embargo, el hecho no deja de presentar facetas curiosas. Para Carlos Astiz dichas relaciones son sumamente formales y afirma: "...es un

"Report by Chischerin on the 3rd session of the CPSU Central Executive Gomittee, 4 march 1925. Frus, 1927, I, 362. Extractos en Clissold, Stephen, Soviet Relations with Latin America (1918-68). "A Documentary Survey", Oxford University Press, London, New York, Toronto, 1970, p. 77. 
hecho conocido que todos los viajeros que utilizan la ruta aérea a través de México y hacia Cuba son cuidadosamente identificados y que esa información es transmitida a los organismos de seguriclad. de los Estados Unidos... también se sabe que el gobierno mexicano se ha preocupado mucho por dificultar la entracla a México de libros y propaganda cubana... Aquí no se intenta efectuar ninguna crítica... por el contrario, se reconoce la capacidad de este país de encontrar un común denominador entre el interés de los Estados Unidos y lo que parece ser el sentimiento de la mayoría de la población mexicana. ${ }^{6}$

Con respecto a los países no-alineados caben más consideraciones. La primera de ellas referida al papel que Mréxico se autoasigna a nivel internacional.

Los dirigentes de este país en numerosas oportunidades declararon la no-alineación y en función de ella muchas veces automarginaron al país. Así se evita alcanzar la categoría de miembro no permanente del Consejo de Seguridad de la ONU para no verse mezclado en conflictos.

Esta actitud, que bien puede ser citada como realista en el sentido de no desperdiciar recursos en "cruzadas de prestigio", contradice uno de los principales fundamentos de los no-alinéados cual es aquel que afirma la activa participación en todos los asuntos y foros internacionales y para este caso particular la ONU, en donde ellos se sienten pares ante sus ayer dominadores.

Dentro del contexto de la ONU cabe señalar la actitud de México frente al colonialismo. El voto ha sido positivo en las votaciones por lista referidas a las medidas tendientes a agilizar el proceso hacia la independencia de los territorios sin autogobierno. Sin embargo, cuando las metrópolis se han mostrado dispuestas a aceptar resoluciones conciliatorias, México ha votado junto a éstas en contra de las posturas anticolonialistas más ortodoxas.

México no ha observado una regular concurrencia a las reuniones de los no-alineados. Si bien ya expresamos nuestra opinión respecto a la validez del indicador concurrencias, pensamos que la inasistencia deliberada está expresando al menos una despreocupación manifiesta. Tomando las tres últimas reuniones, no asistió a DarEs-Salam ni a Lusaka, enviando un observador a la conferencia de Guyana -agosto 1972.

Concluyenclo lo que en su momento constituyó una revolución agraria se ha transformado sustanciaImente. Esta transformación supuso dejar de lado un gran número de postulados revolucionarios

${ }^{\circ}$ Ver en Astiz, Carlos, Latin American International Politics, University of Notre Dame Press, Notre Dame, Londres, 1969. 
estableciendo a la vez reglas de juego compartidas con los EE.UU.; en síntesis, una "doble identiclad". Por un lado la tradición revolucionaria y por el otro las exigencias del México contemporáneo: inversiones, mercados y eficientes relaciones con su vecino.

Ahora bien, chasta qué punto la "doble identidad" se aproxima a esa heterogeneidad constituida por los países no-alineados? Creemos que si existen puntos en común ellos no dejan de ser circunstanciales. A México le es más provechosa la "identidad" que le permite consolidar el actual régimen y a la vez proyectarlo, que el principismo a veces comprometedor de los países no-alineados.

El pensamiento social-demócrata no ha sido ajenos al principismo en política exterior. La heterogeneidad nos permite ubicar en esta internacional entre otros al Partido de la Liberación Nacional de Costa Rica, Acción Democrática en Venezuela, al APRA del Perút, el Partido Revolucionario Dominicano, etc. Todos ellos en su momento se autocalificaron como la "izquierda democrática" de América. Latina, poniendo especial énfasis en aquellas reformas que sin ser radicales permitieran elevar las condiciones de vida de los sectores medios y bajos.

Como representantes de los sectores medios muchas veces lideraron la alianza policlasista pero cuando ésta entró en crisis -fruto de sus contradicciones internas- rompieron sus compromisos con ella.

Políticamente estos grupos reaparecieron en el continente y a veces con éxito en la década del 60. Algunos llegaron al poder, como Figueres en Costa Rica y Betancourt en Venezuela bajo los auspicios del liberalismo kennedyano y de la Alianza para el Progreso.

Si alguna vez la internacional social-demócrata sostuvo posturas independentistas - de donde podríamos establecer vínculos con los no-alineados- no dejaron de ser enfoques teóricos, pues la realidad nos muestra lo contrario. Conservando resabios al tipo guerra fría estos grupos se han identificado fuertemente como partes del "mundo occidental" y en general como pronorteamericanos, país al cual sólo le cuestionan la manifestación formal de su agobiante presencia mientras que aceptan calladamente el contenido de la misma.

Cuán difícil resulta entonces precisar los puntos de aproximación con la temática de los no-alineados, aun aceptando para éstos los casos aberrantes.

En cuanto a las relaciones e identidades que se podrían establecer entre los modelos populistas y los países no-alineados debemos previamente reconocer la diversidad de los populismos latinoamericanos. Así el "perezjimenismo" en Venezuela o el "pinillismo" en

?Para algunos autores el APRA constituiria un caso sui géneris de populismo. 
Colombia caracterizados muchas veces como populistas no presentan ningún tipo de elementos comunes al grupo no-alineado.

Ninguno de estos dos gobiernos presentaron tesis independentistas en materia de política exterior (no cabe aquí juzgar los aspectos internos), por el contrario, su posición anticomunista militante limitó eventuales aproximaciones a países que no adscribían a bloques y para este caso el occidental. El caso colombiano es muy particular, fue un presidente "acuerdista" y liberal -Carlos Lleras- quien, sos" tuvo tesis más afines a los postulados de la no-alineación al enfrentar en términos a veces severos a los entes internacionales - de allí el conflicto con el F.M.I. - y a los países que pretendieron torcer el programa de su gobierno.

Aceptando la calificación de populista para los gobiernos de los generales Ovando y Torres en Bolivia, se pueden establecer algunas relaciones entre este país y los no-alineados.

Durante el gobierno de Ovando el general Torres - que había sido desplazado de la cúpula militar- es enviado como observador a la Reunión de Lusaka. Luego al ocupar Torres la presidencia declarará en La Paz que Bolivia se enrola entre los países del Tercer Mundo en la lucha por la liberación nacional.

La Argentina y Brasil constituyen -sea cual fuere el régimen político de turno- dos casos muy particulares. Si como afirmamos al comenzar este análisis las diferencias existentes entre los continentes americano, asiático y africano eran notables, las diferencias para el caso de estos dos paises son aún más notorias.

La Argentina durante el gobierno del general Perón sostuvo la denominada Tercera Posición. Ya adelantamos que la misma hacía referencia no sólo a un tercerismo internacional sino más bien a una nueva alternativa doctrinaria que escapaba a las rigideces del capitalismo y del colectivismo.

En este sentido la política exterior tercerista usó las dos vías de la "contestación" a la potencia hegemónica: la continentalización y el establecimiento de relaciones diplomáticas con la Unión Soviética.

La vía continentalista fue sin duda alguna la más relevante. La firma de los numerosos tratados de unión económica con países latinoamericanos señaló una tenclencia auspiciosa en el sistema interamericano. Por otra parte, a través de las embajadas $y$ misiones ad hoc se exportó el tercerismo y el justicialismo.

No hubo casi ningún vínculo institucional entre el justicialismo y el agrupamiento de los no-alineados; en 1955 caía Perón mientras que en ese mismo año se inauguraba lạ Reunión de Bandung. De

'A Bandung el gobierno del Gral. Perón envió "observadores". 
allí en adelante la. Argentina asistió en calidad de observador a las reuniones de los no-alineados y si bien oficialmente no presentó moción alguna, a nivel extraoficial aprovechó de esos eventos para hacer conocer a los países asistentes la posición del país frente al problema de las Islas Malvinas.

Brasil conforma también un caso especial. El populismo de Vargas mantuvo la política iniciada por el "branquismo" o sea no cuestionar el liderazgo norteamericano en el área.

Las relaciones con la Unión Soviética sufrieron altibajos; entre 1945 y 1947 las hubo pero de ninguna manera se debe inferir de las mismas una "contestación"; las causas hay que buscarlas en la misma estructura del sistema internacional por ese entonces no signado por la guerra fría. Tampoco existió una intencionalidad continentalista. En este aspecto el único antecedente habría que ubicarlo en los años 40 cuando Brasil firma con la Argentina un tratado en cuyo Preámbulo se mencionaba una futura Unión Económica Aduanera.

Esta actitud brasileña mantiene coherencia con la asistencia, en enero de 1941, a la Conferencia Económica Regional del Río de la Plata celebrada en Montevideo. No existió en esto ninguna intención de hostigamiento a los EE.UU., sólo se trataba de una reacción frente a las perniciosas consecuencias que a las economías regionales ocasionaba el conflicto bélico.

En los años 50, cuando Perón le da impulso a la idea continentalista, Brasil rechaza la postura. La militancia occidental brasileña era manifiesta. En la IV Reunión de Consulta de la OEA es Brasil quien presenta junto a los EE.UU. un proyecto por el cual se requería a la Junta Interamericana de Defensa la elaboración de planes para la defensa del hemisferio, a lo que la Argentina, México y Guatemala se opusieron. En 1954 reitera el pro-norteamëricanismo votando en marzo de ese año la "Declaración de Solidaridad para la Preservación de la Integridad Política de los Estados Americanos contra la Intervención del Comunismo Internacional", frente a la cual se abstuvieron la Argentina y México con el voto negativo de Guatemala, contra quien en realidad estaba dirigida la Declaración (Arbenz) .

Kubitschek sin abandonar el pro-norteamericanismo firma en diciembre. de 1959 un importante acuerdo comercial con la Unión Soviética. Este acuerdo se produjo luego del deshielo de 1959 y en él subyacía la idea de anticiparse a futuros acuerdos entre las potencias.

Con referencia a la relación Brasil-países no-alineados caben por lo menos dos consideraciones. En primer lugar la denominada "po- 
lítica exterior independiente" instrumentada por los presidentes Quadros y Goulart, y en segundo término la apertura africana.

La "política exterior independiente" iniciada por Quadros no dejó de ser alternativa para un gobierno sin estructura partidaria propia y con un Parlamento en manos de las fuerzas derrotadas en la elección presidencial. Al inmovilismo interno se lo pretendió superar con actitudes externas simbólicas, algunas de las cuales deterioraban al mismo gobierno como fue la condecoración al Che Guevara. En los mismos términos podemos juzgar al sucesor, Goulart, si bien para este caso nos aproximamos a la crisis del populismo clásico.

La apertura al Africa reconoce causales económicas y políticas. El temor a ver desplazados los productos primarios tropicales brasileños por similares africanos (caso café) y la posibilidad de constituirse en interlocutor occidental en el continente africano usando de los rasgos de cultura y raza.

En el orden económico se destaca el Acuerdo firmado en 1961 con la Organización Interafricana del Café, en donde se pone de evidencia la necesidad de establecer lazos ya no a nivel principista o declarativo, sino en el plano de los temas específicos.

Brasil no abandonó su política africana, más, ha tratado de racionalizarla a pesar de los inconvenientes que le origina su particular relación con Portugal. Establece relaciones diplomáticas con Ghana, Nigeria y Senegal y en el año 1963 llegó a comprometer 20 millones de dólares para la futura creación de un Banco de Desarrollo Regional.

El gobierno militar también ha mantenido esta línea: mantiene relaciones amistosas con varios países africanos como Senegal, Costa de Marfil, Ghana, Dahomey, Camerún y Zaire. De 1964 a 1971 el comercio entre Brasil y África aumentó un 311 por ciento.

También Brasil ha conseguido algunos aliados oficiosos, como el ideólogo Senghor del Senegal (país para el cual Brasil es el país No 2 en materia de comercio) quien se refiere a la "Gran comunidad afrobrasileña". Finalmente, Brasil ha logrado formar parte del BAD (Banco Africano de Desarrollo) suscribiendo acciones por un valor de 2 millones de dólares siendo el único país latinoamericano en obtener esta "cabecera de puente".

A pesar de la contradicción existente entre el apoyo a la política colonial portuguesa y el principismo no-alineado, Brasil asiste regularmente a las reuniones de estos países en calidad de observador. Esto le ha permitido no sólo explotar una imagen "negra" sino que hábilmente su diplomacia ha conseguido evitar resoluciones condenatorias para con su política frente a Portugal. Así, en Lusaka el Secretario de la Unión Africana (OUA) hizo circular entre los 
asistentes un proyecto de resolución que condenaba a Brasil por las mismas razones, planteo que fue reiterado en la reciente Reunión de Guyana.

De manera que la presencia brasileña no constituye un indicador para deducir de ella una contestación o adscripción ideológica, más bien se la debe interpretar sirviendo a intereses específicos y concretos.

La focalización latinoamericana dirigida hacia temas especificos, además de ser operativa, constituye la única posibilidad de amalgamar intereses comunes. Así Perú, además de reseñar en las últimas reuniones de los no-alineados (en donde como observador envió al Canciller Gral. Mercado Jarrín dándole así significación a la presencia) los logros de la Revolución -nacionalizaciones, ley de comunidad industrial, reforma agraria, etc.-, ha tratado de obtener el apoyo de los países africanos y asiáticos para su tesis referida a las 200 millas.

Igual actitud han clemostrado Bolivia y Ghile. EI primero ha expuesto sus clásicas reivindicaciones relacionadas a su mediterraneidad y Chile divulgó los logros de la vía socialista del Presidente Allende a la vez que requería también el apoyo para el tema de las 200 millas.

Este país juntamente con Cuba y Guyana pertenecen a la categoría de miembros plenos entre los no-alineados. En la Reunión de Argel -1973- Perú y la Argentina fueron admitidos como miembros plenos. En las diversas reuniones Guba ha demostrado prudencia $\mathrm{y}$ no ha planteado enfrentamientos con ningún régimen latinoamericano a la vez que Guyana ha apoyado en todo momento a los movimientos de liberación africanos para los cuales ha pedido apoyo material.

Perú y Chile obtuvieron resultados positivos en la Reunión de Guyana. Así la Declaración de Georgetown expresa entre sus párrafos finales:

"La Conferencia examinó la situación cle América Latina y expresó su pleno apoyo al gobierno de la Unidad Popular de Chile, empeñando en consolidar su independencia nacional, eliminar la dominación imperialista y edificar una nueva sociedad; a las medidas nacionalistas puestas en práctica por el gobierno de Perú y sus esfuerzos por defender la soberanía nacional y promover el progreso social".

Con referencia a los derechos del mar expresa también la Declaración:

"La Conferencia reconoció el derecho de los Estados ribereños a ejercer su soberanía sobre los recursos naturales situados dentro de los límites de sus respectivas jurisclicciones nacionales". 


\section{CONGLUSIONES}

Lo expuesto avala la viabilidad de una política latinoamericana de aproximación a los países no-alineados. El elemento común debe ser la solidaridad basada en intereses y problemas comunes evitando en todo momento el declaracionismo estéril.

Nuestros países buscan el logro de una mayor autonomía; ésta es la lucha por la liberación, de allí la necesidad de hallar instrumentos idóneos en materia de política exterior. Pensamos que América Latina mostrará realismo y espíritu solidario si encara sus relaciones con Asia y Africa en función de banderas comunes. La etapa esterizante de lo teórico está superada y a través de acuerdos parciales se comienza a vislumbrar un futuro auspicioso.

Los acuerdos del Café, la posición común en la UNCTAD, el Grupo de los "77", la postura unitaria en las negociaciones monetarias, el pool de países productores de petróleo y la solidaridad de los países productores de cobre para con Chile son ejemplos de búsqueda y hallazgo de posiciones y objetivos comunes: la liberación de Pueblos y Naciones. ${ }^{9}$

-A estos ejemplos debe agregarse la creación de la Organización Latinoamericana de Energía (OLADE). Esta organización es en buen ejemplo de países que maximizan sus recursos frente a los paises industriales. Así en los considerandos "reafirman la necesidad de coordinar una acción solidaria por medio de la OLADE, para alcanzar el objetivo de defender, frente a acciones, sanciones o coerciones, las medidas que los paises hayan adoptado o adopten en ejercicio de su soberanía, en procura de preservar los recursos naturales, particularmente los energéticos".

La OLADE tiene sede en Quito y fue creada en abril de 1973. 